CHINESE JOURNAL OF GEOPHYSICS Vol.49, No.3, 2006, pp: 627 636

\title{
VEGETATION VARIATIONS ALONG THE MONSOON BOUNDARY ZONE IN EAST ASIA
}

\author{
OU Ting-Hai QIAN Wei-Hong \\ Department of Atmospheric Sciences, Peking University, Beijing 100871, China
}

\begin{abstract}
Regional features and relationships between vegetation and climate variables have been detected in many previous work from regional and global scales. This paper analyzes the relationship between the vegetation variation and climate change along the monsoon boundary zone (MBZ) in East Asia at seasonal and interannual timescales. The comparison analysis for the monsoon region, the non-monsoon region and the MBZ suggests that the response of vegetation growth to climate change is relatively sensitive in the MBZ.
\end{abstract}

Key words Monsoon boundary zone (MBZ), Normalized Difference Vegetation Index (NDVI), East Asia, Climate factor, Interannual variation

\section{INTRODUCTION}

China is strongly influenced by the East Asian monsoon. During the winter half year the climate is mainly clod and dry. Cold surges, strong windy accompanied with sand storm are the major interannual climate events particularly observed in northern China. During summer periods, the rain belt moves and rainfall decreases gradually from south to north with the hot and humid climate in eastern China. Large precipitation variability is one of major features in China. In some years rainfalls are abundant enough to cause floods while in other years they are too deficit to support agriculture from place to place. The regional characteristics of climate variability are outstanding in China. In northern China between $35^{\circ} \mathrm{N}$ and $45^{\circ} \mathrm{N}$ where a zone oriented from southwest to northeast is so called the crossing zone with the activity of agriculture and pasture ${ }^{[1]}$. Along the zone, large gradients from aspects of rainfall and heating (radiation) are notable. This zone is also referred the transitional climate zone and biome boundaries in China ${ }^{[2]}$. Climatologically, the zone has a width formed from the last boundary of each summer monsoon in East Asia. The last boundary has interannual and interdecadal variability. In this paper, we call this zone as monsoon boundary zone (MBZ). Shi et al. ${ }^{[3]}$ defined the MBZ where annual rainfall amount is about $200 \sim 500 \mathrm{~mm}$. We think that the MBZ in the northwest area is too large by using this definition, and it's more reasonable by using annual rainfall $300 \sim 500 \mathrm{~mm}$, and considering the marching and retreat of rain belt during weaker and stronger monsoon years.

Because of the special geography situation and topography distribution, climate of China has been influenced by South Asia monsoon, East Asia monsoon and west wind at middle latitudes, which lead to differences of regional climate, vegetation types and soil textures in different areas. In different climate regions, the influence of rainfall and sunlight concentrating periods varies with different vegetation types. The influence periods of former rainfall and accumulated temperature to vegetation also change spatially ${ }^{[4]}$. The response of net primary production to climate change varies with different vegetation types ${ }^{[5]}$. Researchers have to consider different vegetation types regionally when studying the influence of climate on vegetation ${ }^{[6]}$. In recent work of Fang et al. ${ }^{[7,8]}$, the change of different vegetation types and the influence of climate on vegetation has been studied by defining forest, grassland, desert, alpine vegetation, and cropland regions. From their work we can find the response of vegetation to climate is sensitive in MBZ, but there was no detailed explanation. This work will study the reason of sensitive response of vegetation to climate change in the special area, MBZ.

E-mail: othpz98@sina.com.cn 


\section{DATA AND METHOD}

\subsection{Temperature and Precipitation Data}

Daily mean air temperature and precipitation at totally 726 stations in the mainland of China for 1951 2000 are collected from Chinese Meteorological Administration. Only the data of 444 stations has been used in our research after data checking as shown in Fig. 1. In order to coincide with the time period of Normalized Difference Vegetation Index (NDVI) data, the time period of daily temperature and precipitation data is chosen as 1982 1999. There is very small number of missing data in the selected period of daily temperature and precipitation data, with the largest number of missing data little than 10 times per station, and linear interpolation is used to fill the missing data. The accumulative temperature (AT) is calculated from January to May with the temperature larger than 0 degree for spring and from January to August with the temperature larger than 0 degree for summer.
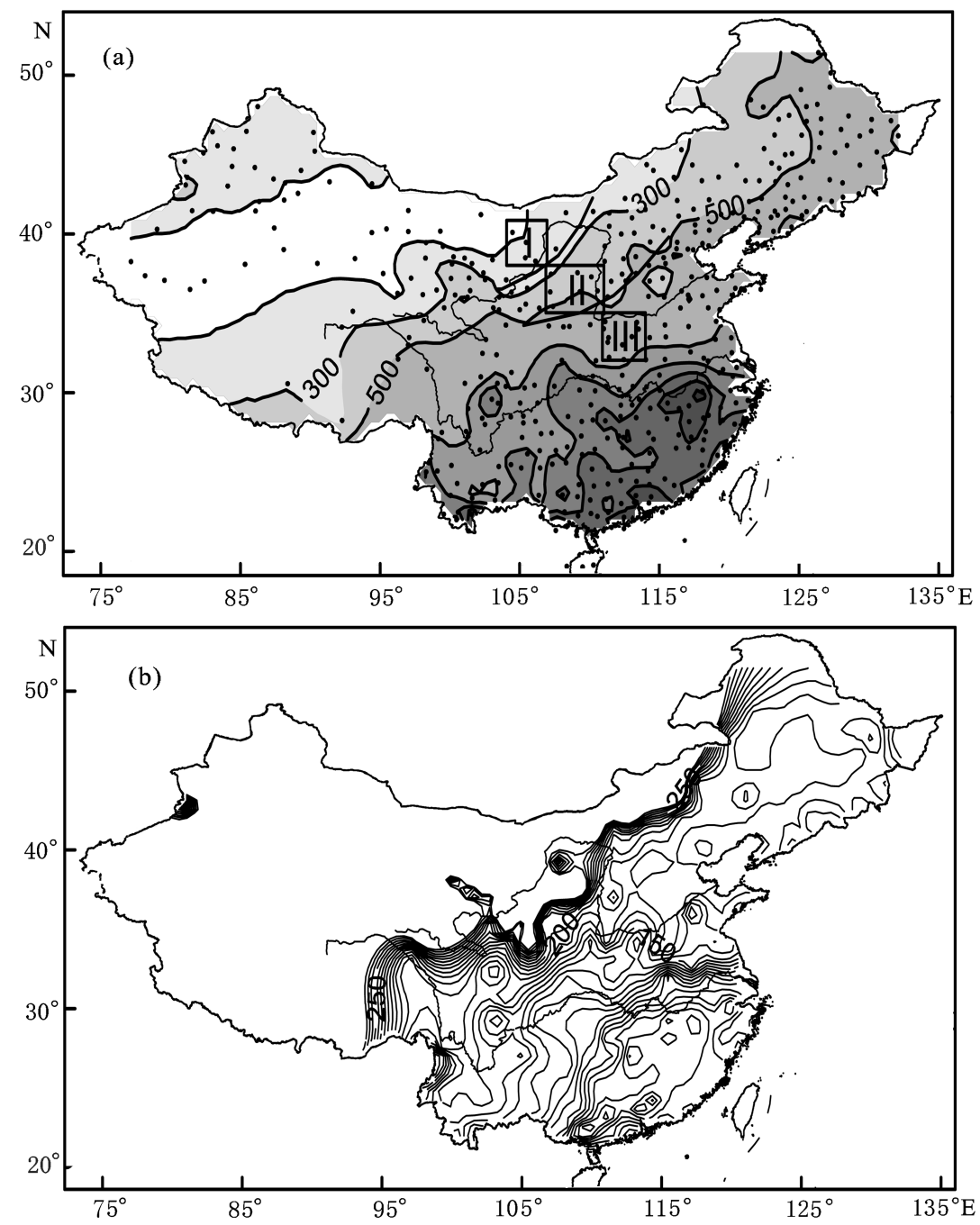

Fig. 1 (a) Distribution of annual mean precipitation during 1982 1999 (dots indicate the observation stations used),

(b) isochrones of $5 \mathrm{~mm}$ precipitation moving northward relative to the calendar date of 1 January, averaged for 18 years from 1982 to 1999, 7-day running mean is used for the precipitation

In (a), two heavy solid lines indicate the monsoon boundary zone from $300 \mathrm{~mm}$ to $500 \mathrm{~mm}$ of annual mean precipitation.

Box I, Box II, Box III are used to represent the non-monsoon region, the MBZ and the monsoon region, respectively. 
When considering the influence of rainfall and temperature on the vegetation, Available Precipitation Index (API) is defined as the following:

$$
\mathrm{API}=\Delta P / S_{\mathrm{P}}-\Delta \mathrm{AT} / S_{\mathrm{AT}},
$$

where $\Delta \mathrm{AT}$ and $\Delta P$ denote the spring (summer) AT and spring (summer) total rainfall anomaly, respectively, based on the average of time period 1982 1999; and $S_{\mathrm{AT}}$ and $S_{\mathrm{P}}$ indicate standard deviation of AT and rainfall, respectively. AT can be used to indicate the vaporizing ability. The larger AT, the stronger the vaporizing ability, this has negative contribution to water resource. The larger the API, the more the available water, and vice versa. More or less available water has negative influence on vegetation growth.

\subsection{NDVI Data}

One of the important parts of climate research is to study the influence of climate on the ecosystem. The response of vegetation to the climate change is the most sensitive one in the ecosystem, on which people focus their attention. The response of vegetation to climate change is more sensitive in the MBZ for the special climatology condition. Zhang et al. ${ }^{[9]}$ used the leaf area to study the response of vegetation to rainfall and temperature. The Normalized Difference Vegetation Index (NDVI) derived from satellites has good relation with green-leaf biomass and green-leaf area ${ }^{[10]}$. It can be used to illustrate the vegetation situation ${ }^{[11]}$, which has some special advantage when studying the climate and climate change ${ }^{[12]}$. By using NDVI data we can study the cycle of global vegetation (beginning, maximum and ending), the zonal character of vegetation distribution ${ }^{[13]}$, and the different influence of globe warming on the growth and distribution of the land ecosystem ${ }^{[14 \sim 16]}$.

The NDVI data used in this paper is from the Advanced Very High Resolution Radiometer (AVHRR) on the National Oceanic and Atmospheric Administration (NOAA) polar-orbiting satellite (http://eosdata.gsfc.nasa.gov). The spatial resolution is $1^{\circ} \times 1^{\circ}$ latitude by longitude with 10-day interval, for the period January 1981 to December 2000. To compare with the climate data the NDVI data are interpolated into stations in China.

As indicated by Gong and $\mathrm{Ho}^{[17]}$, larger error comes from the lower NDVI value when the NDVI reaches zero. In northern China the relatively lower NDVI are found in winter but in this season the lower NDVI are larger than 0.05 so that this kind of errors is not crucial in this paper.

In this paper, the annual vegetation increase rate (AVIR) is defined as

$$
\mathrm{AVIR}=\frac{1}{\overline{\mathrm{NDVI}}}\left(\frac{\sum_{i=23}^{25} \mathrm{NDVI}_{i}}{3}-\frac{\sum_{i=5}^{7} \mathrm{NDVI}_{i}}{3}\right),
$$

where NDVI indicates the mean of NDVI for 1982 1999, $\sum_{i=5}^{7} \mathrm{NDVI}_{i}$ is the sum of NDVI from $5^{\text {th }}$ 10-day to the $7^{\text {th }} 10$-day (i.e., from late February to early March) and $\sum_{i=23}^{25} \mathrm{NDVI}_{i}$ is the sum of NDVI from $23^{\text {th }} 10$-day to the $25^{\text {th }} 10$-day (i.e., from late August to early September) related to January 1 each year, which indicates the average annual vegetation condition, the vegetation status on the last day of winter and summer, respectively. The difference indicates the increase of NDVI in growing season, which can be used to illustrate the change of vegetation in growing season and the annual change of vegetation. The relative change of vegetation can be reflected through dividing the difference by the climate average.

\section{REGIONAL FEATURES OF NDVI AND CLIMATE}

\subsection{MBZ of the East Asia Monsoon}

The Asia monsoon is one of the most important parts of the world monsoon ${ }^{[18]}$. The East Asia monsoon is a sub-system of the Asia monsoon, which has great influence on the climate and economy of East Asia. Huang 
et al. ${ }^{[19]}$ reviewed the seasonal, annual and interannual changes of the East Asia monsoon (especially the East Asia summer monsoon) and its mechanism. The marching of the East Asia monsoon is similar to the study result of Tao et al. ${ }^{[20]}$. In the period of northward marching of the East Asia monsoon, we can see that it will stay around $40^{\circ} \mathrm{N}$ for a period and then draw back to the south. From this we can say that there is a boundary area nearby $40^{\circ} \mathrm{N}$, but it is difficult to define the accurate location of MBZ. In order to define the MBZ, first we look at the marching of the East Asia monsoon. Fig. $1 \mathrm{~b}$ shows the contours of $5 \mathrm{~mm}$ rainfall relative to 1 January from 1982 to 1999. Climatologically, rainfall started originally from southeastern China in February and then the isochrone moved northward with about three steps in eastern China. Concentrated isochrones indicate the rainfall standing there many days. From 130-day to 170-day in early June isochrones stand basically in the north of the lower Yellow River east of $110^{\circ} \mathrm{E}$. After this isochrone moved northward faster and concentrated isochrones drifted from central Hetao region to North China from 200-day to 220-day in the last ten days of July. There was no $5 \mathrm{~mm}$ rainfall in the area north to the concentrating isochrone zone. From this we can say that this concentrating isochrone zone determines the monsoon and non-monsoon regions of China. But the concentrating isochrone zone isn't always located in the same area. The annual and interannual changes of the concentrating isochrones decide the region of MBZ.

Shi et al. ${ }^{[3]}$ defined the MBZ where annual rainfall amount is about $200 \sim 500 \mathrm{~mm}$. From Fig. $1 \mathrm{~b}$ we find that the MBZ in the Northwest China is too large by using this definition, and the influence of strong/weak monsoon on the rainfall has not been considered. It's more reasonable by using annual rainfall $300 \sim 500 \mathrm{~mm}$, considering the marching and retreat of the rain belts during weaker and stronger monsoon years. Fig. 1a shows the areas where the annual rainfall distribution is larger than $1500 \mathrm{~mm}$ in southeastern China and less than $100 \mathrm{~mm}$ in northwestern China. A large gradient zone could be observed between them particularly between two contours of $300 \mathrm{~mm}$ and $500 \mathrm{~mm}$. Three boxes, Box I $\left(104^{\circ} \mathrm{E} \sim 107^{\circ} \mathrm{E}, 38^{\circ} \mathrm{N} \sim 41^{\circ} \mathrm{N}\right)$, Box II $\left(107^{\circ} \mathrm{E} \sim 110^{\circ} \mathrm{E}\right.$, $\left.35^{\circ} \mathrm{N} \sim 38^{\circ} \mathrm{N}\right)$ and Box III $\left(111^{\circ} \mathrm{E} \sim 114^{\circ} \mathrm{E}, 32^{\circ} \mathrm{N} \sim 35^{\circ} \mathrm{N}\right)$ are used to represent the non-monsoon region, the $\mathrm{MBZ}$ and the monsoon region, respectively.

In order to determine the MBZ region, the East Asia monsoon index ${ }^{[21]}$, which is well correlated with subtropical high, has been chosen to divide the stronger/weaker monsoon years. The East Asia monsoon index indicates that the strong monsoon occurred in 1985, 1990 and 1994 while the weak monsoon appeared in 1983, 1987, 1991, 1993 and 1995. The average annual rainfall has been calculated separately for weaker and stronger monsoon years (Fig. 2(a,c)). The annual rainfall variation ratio has been calculated by dividing rainfall anomaly by average annual rainfall for stronger/weaker monsoon years, respectively (Fig. 2(b,d)). From Fig. 2(a,c) we find that in the stronger monsoon years the annual rainfall $300 \mathrm{~mm} \sim 500 \mathrm{~mm}$ area was located in the north of the same defined area with climate average. But in the weaker monsoon years the change of location was not obvious. It can also be found from annual rainfall variation ratio (Fig. 2(b,d)). In the stronger monsoon years the variation ratio increased largely in the MBZ and areas south to it, but the change in weaker monsoon years was not obvious. In the stronger monsoon years the ridge of subtropical high western marching into inner land which increased the rainfall at higher latitudes and decreased the rainfall in the Yangtze River Basin. But in the weaker monsoon years the ridge of subtropical high drew back to the ocean, and the rainfall in the MBZ region decreased. As a whole, the increasing of annual rainfall in MBZ region in stronger monsoon years is larger than the decreasing of annual rainfall in weaker monsoon years. No matter in stronger or in weaker monsoon years the increasing or decreasing rainfall was located south to the line of $300 \mathrm{~mm}$ rainfall of stronger monsoon years. From this we define the location of $300 \mathrm{~mm}$ rainfall of stronger monsoon years is the northern margin of MBZ. When defining the southern margin of MBZ the annual average rainfall, $5 \mathrm{~mm}$ rainfall concentrating isochrones and variation ratio of annual rainfall have been considered. The southern margin of MBZ has been defined by the location of $500 \mathrm{~mm}$ rainfall of weaker monsoon years.

\subsection{NDVI Seasonal and Interannual Variations}

In order to see seasonal variations of vegetation, Fig. 3 shows a set of maps of seasonal mean NDVI for 1982 1999. The maps cover the regions including China and Mongolia. In summer and autumn an obviously 
Ou T H et al.: Vegetation Variations along the Monsoon Boundary Zone in East Asia
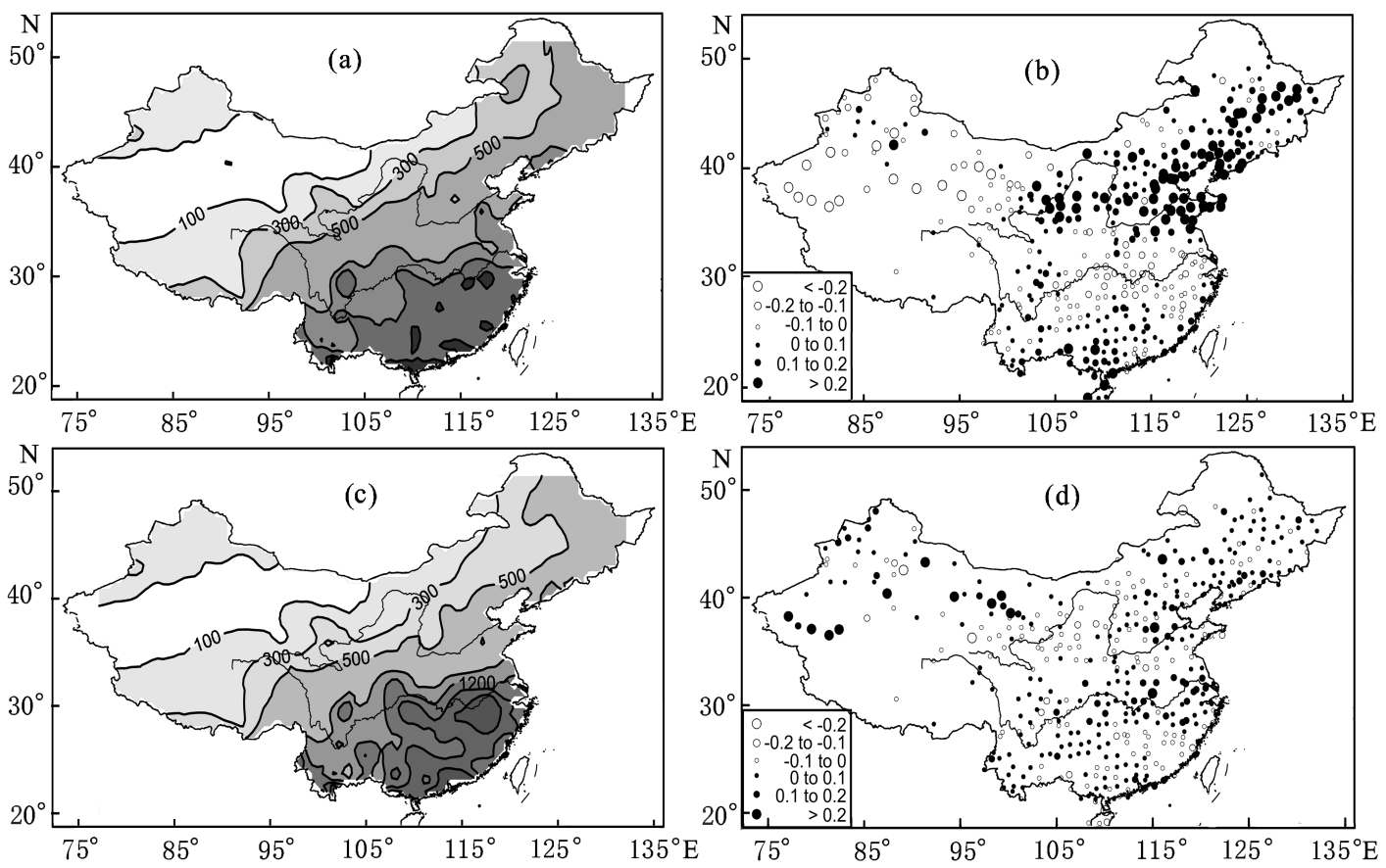

Fig. 2 Annual mean precipitation ( $\mathrm{mm}$ ) for (a) stronger and (c) weaker monsoon years, relative variation of precipitation for (b) stronger and (d) weaker monsoon years Solid circle indicates the increasing rainfall, hollow circle indicates the decreasing rainfall.
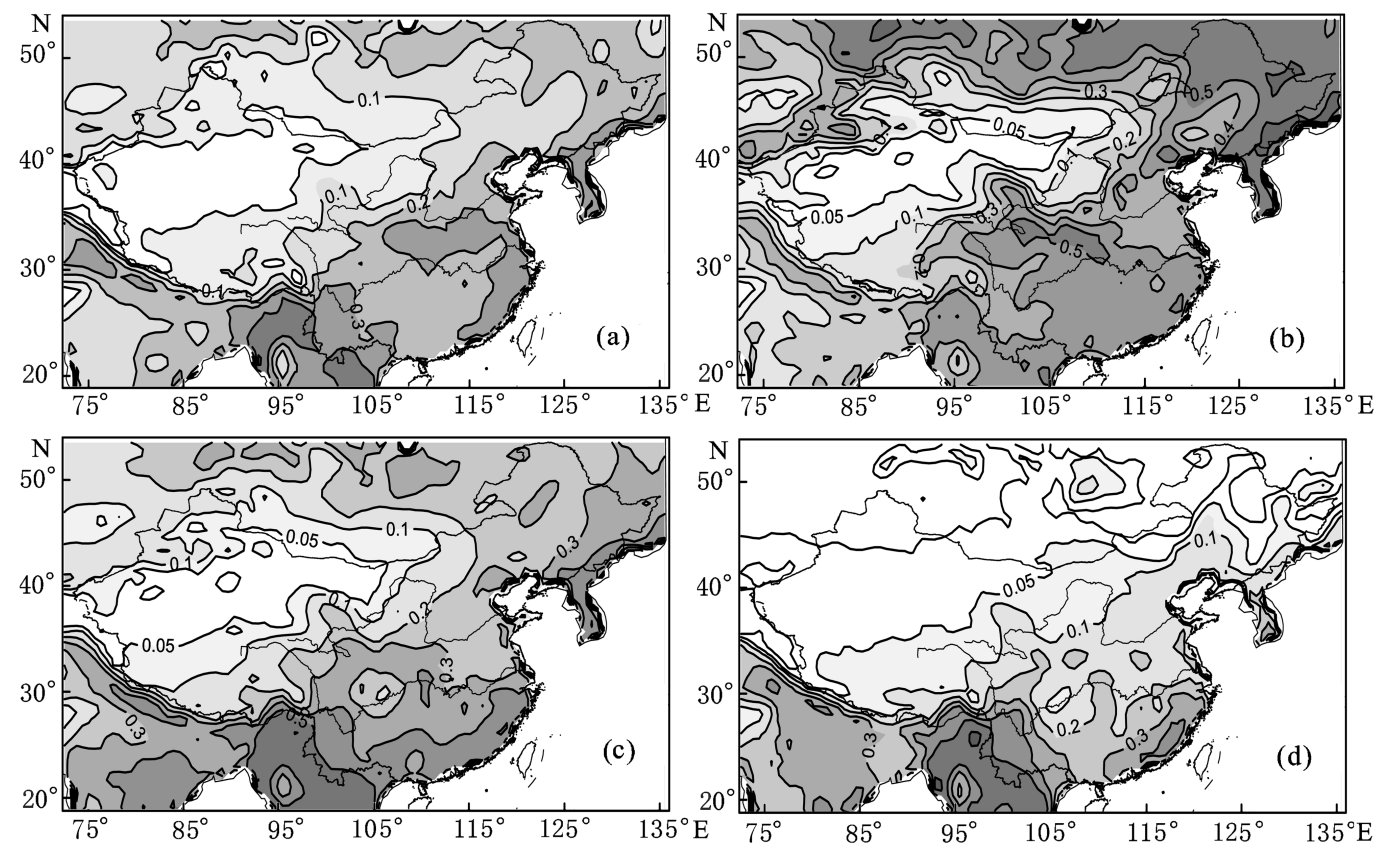

Fig. 3 Distributions of seasonal mean NDVI calculated from the 18-year period for 1982 1999 (a) Spring (MAM); (b) Summer (JJA); (c) Autumn (SON); (d) Winter (DJF). Blank areas indicate the value of NDVI littler than 0.05 .

trending east low-value zone of NDVI existed in northern China and southern Mongolia along $40^{\circ} \mathrm{N}$. But it disappeared in winter for the lowest temperature which led to lowest NDVI. And this low-value zone along $40^{\circ} \mathrm{N}$ coincide with the area which is influenced by the dry-and-cold west wind. From the distribution of NDVI 


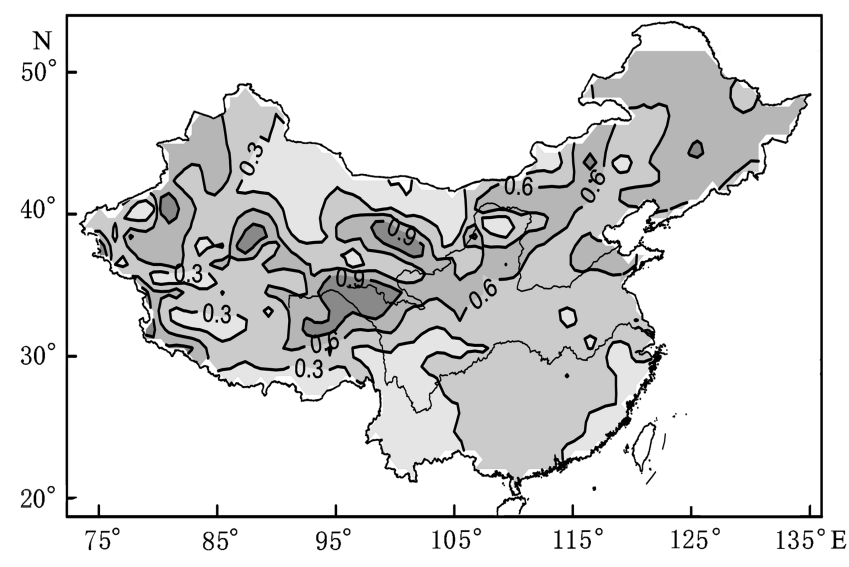

Fig. 4 Mean increase rates of vegetation growth in the period 1982 1999 we can find that the MBZ also is the key region of the marching and withdrawing of vegetation in middlelatitude areas.

The seasonal change of vegetation is obvious in MBZ. And the relative growing ratio is also obvious in MBZ. Fig. 4 shows the distribution of 1982 1999 average of Mean Increase Rate (MIR) $(\mathrm{MIR}=$ $\sum_{i=1}^{18}(\mathrm{AVIR})_{i} / 18$, the formula to calculate AVIR of a selected year, which has been described in Section 2.2). Fig. 4 indicates that the MIR value was remarkable along the MBZ. But it was not remarkable in Yangtze River and the south of Huaihe River, although the annual variations of rainfall and energy condition were also larger in these areas.

\section{VEGETATION VARIATION RESPONSES TO THE CLIMATE CHANGE IN MBZ}

For the special climate condition, vegetation in MBZ response sensitively to the climate change. The variation of vegetation of vegetation inner a year can be largely decided by the change in growing seasons. So we pay more attention to studying the response of vegetation to climate change in growing seasons (spring and summer).

Figures 5 7 show the spatial distribution of correlation between rainfall, AT and API in spring and summer in northern China. We can see from Fig. 5 that in spring although the influence of rainfall on vegetation is not obvious, the AT largely influences the vegetation in spring as indicated by the correlation of API and NDVI. In spring temperature is more important than rainfall to the growing of vegetation. If there is more rainfall with less AT then the available precipitation will be more than the demand for vegetation growing which will block the growth of vegetation. But for summer the demand of rainfall is more important than temperature. The rainfall in spring and summer largely influences the summer vegetation (Fig. 6a, 7a). But the influence of AT in spring and summer on summer vegetation is not obvious. In summer the value of the correlation between spring and summer AT and summer vegetation is negative in selected areas I and II (Fig. 7a), for the demand of precipitation is more important in summer. The spring and summer AT has negative contribution to the growth of vegetation in summer, for the larger AT the less available precipitation. But in the Huaihe River Basin the summer rainfall is relatively larger, which leads to more available precipitation, and the vegetation growth is blocked. The available precipitation will be reduced with the increasing of AT. So we can see in this area the correlation between spring and summer AT and NDVI is obvious (especially between summer AT and summer NDVI).

In order to display and compare the climate variables impacting vegetation activity in different regions near the MBZ, Table 1 lists the correlations between them. The precipitation and temperature (there indicated by AT) are two major important factors for the growth of vegetation. Here we choose two factors to study the influence of climate on the growth of vegetation. Table 1 indicates that the change of AT largely influences the growth of vegetation in spring for the lower average AT, although the demand of water is very important. And the influence of AT on the growth of vegetation is more obvious at higher latitudes (Box I and II) than at lower latitudes (Box III). There is significant influence of AT on the growth of vegetation in MBZ. In spring, the correlation coefficient of $\mathrm{AT} /$ water and vegetation series is positive which indicates that in spring AT and water are all important for the growth of vegetation. In MBZ, the correlation coefficient is significant (0.33 and 0.48 for water and AT, respectively). In the area of lower average temperature, Box I, the AT has stronger influence on the growing of vegetation than water. 


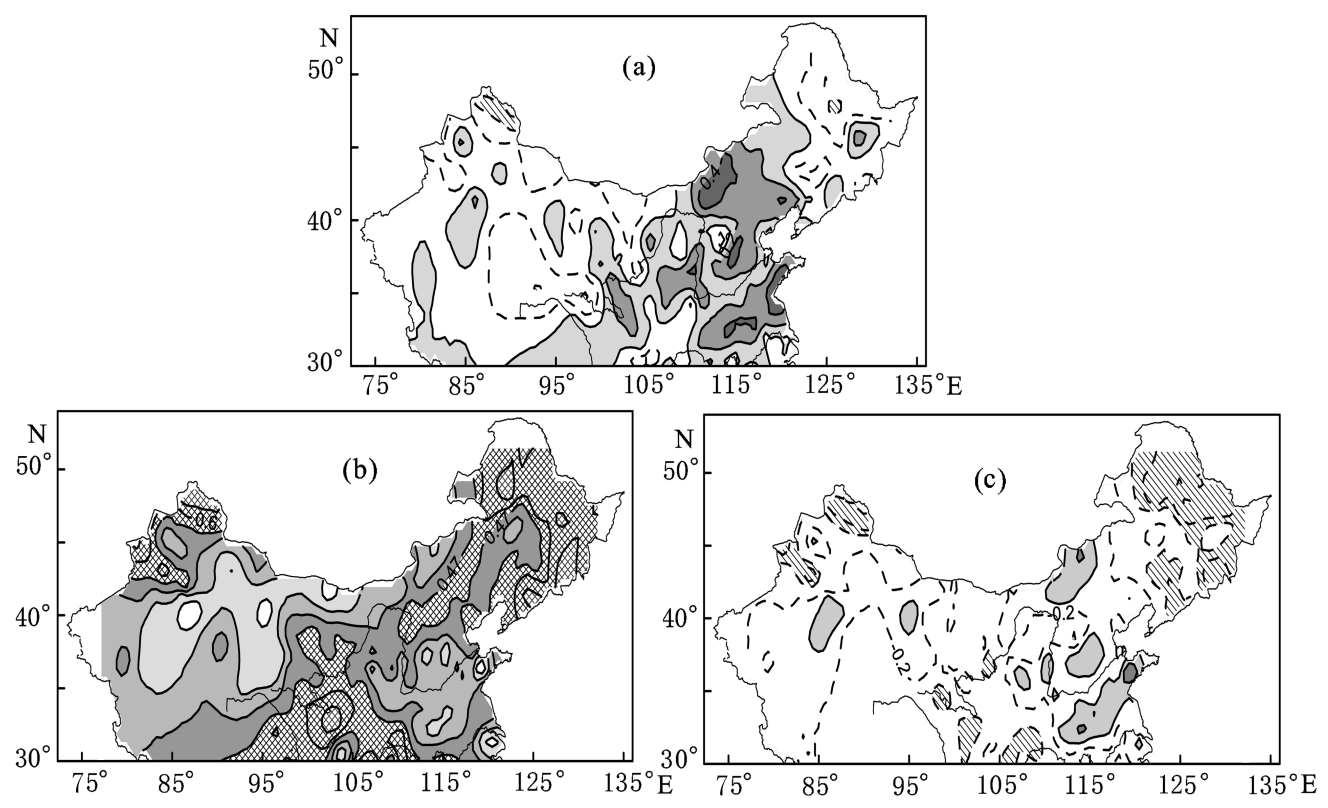

Fig. 5 Distribution of correlation coefficient (a) between spring precipitation and spring NDVI, (b) between spring AT and NDVI in northern China and (c) between spring API and spring NDVI Solid lines indicate the positive correlation coefficient region (darker areas indicate bigger ones), dashed lines indicate the negative correlation coefficient region, gridding and diagonal indicate regions which positive and negative correlation coefficient is significant at the 0.05 level respectively.

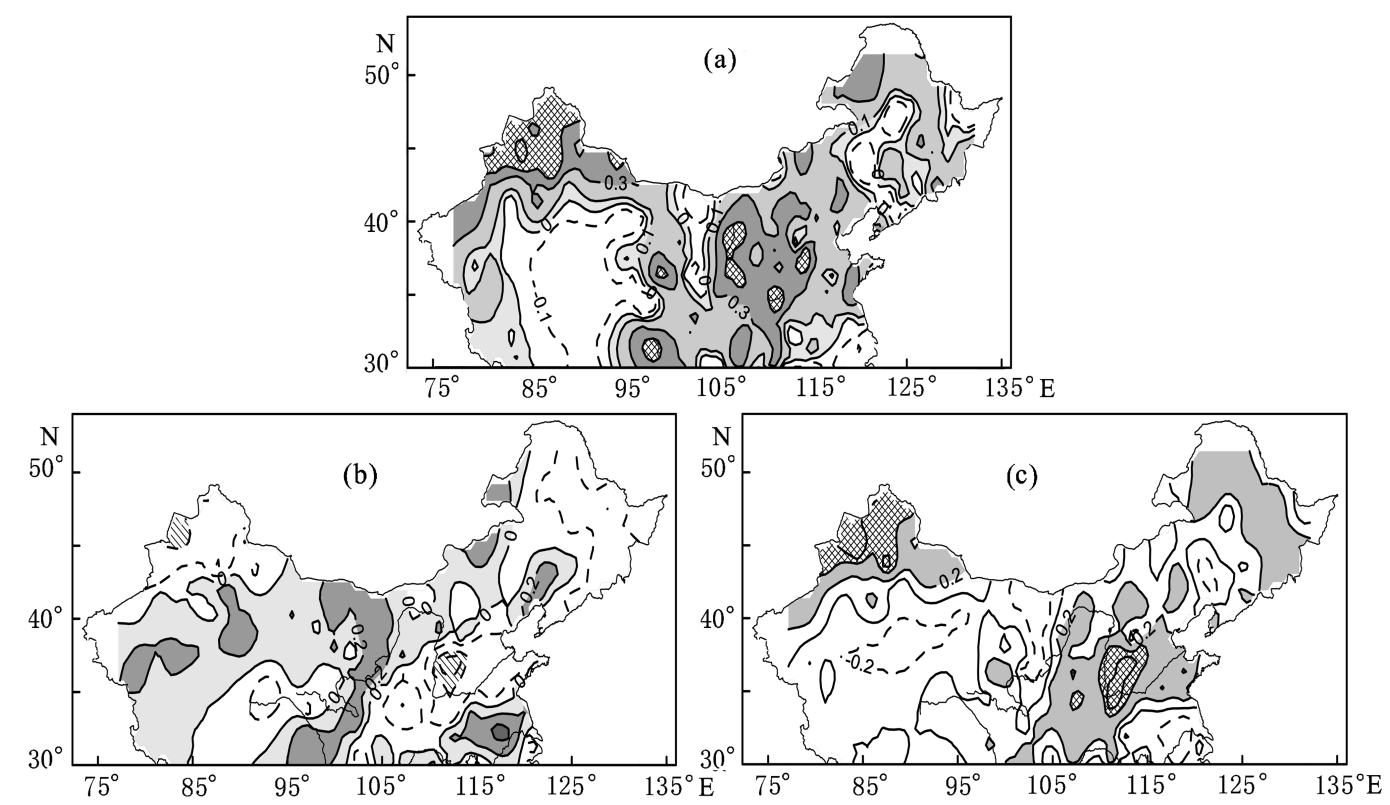

Fig. 6 Same as Fig. 5 but for (a) spring rainfall and summer NDVI, (b) spring AT and summer NDVI, (c) spring API and summer NDVI

In summer, the demand for AT decreases while the temperature growing higher and higher. We can see from Table 1 that only in Box I the correlation between AT and vegetation index is positive in summer, and it is negative in MBZ and the south of MBZ. The demand of water varies for different areas, more water is 
needed in the northern region. The influence of spring water on summer vegetation index is significant with correlation coefficient 0.52 , which indicates the delayed reaction of vegetation movement to water. And the vegetation movement reacts simultaneously to AT.

Table 1 Correlation coefficients between NDVI and climate variables in different seasons for various boxes

\begin{tabular}{l|c|ccc|ccc}
\hline \multirow{2}{*}{} & \multirow{2}{*}{} & \multicolumn{9}{|c}{ NDVI } \\
\cline { 3 - 9 } & & \multicolumn{3}{c}{ Spring } & \multicolumn{3}{c}{ Summer } \\
\cline { 3 - 9 } & & Box I & Box II & Box III & Box I & Box II & Box III \\
\hline \multirow{2}{*}{ Spring } & Rainfall & 0.1 & 0.33 & 0.19 & 0.4 & $0.52^{*}$ & 0.37 \\
& AT & 0.3 & $0.48^{*}$ & 0.21 & 0.32 & -0.09 & -0.22 \\
\hline \multirow{2}{*}{ Summer } & Rainfall & & & 0.37 & 0.34 & 0.22 \\
& AT & & & & 0.22 & -0.22 & -0.31 \\
\hline
\end{tabular}

Note: Sign $*$ indicates the correlation reaching the 0.05 significant level.

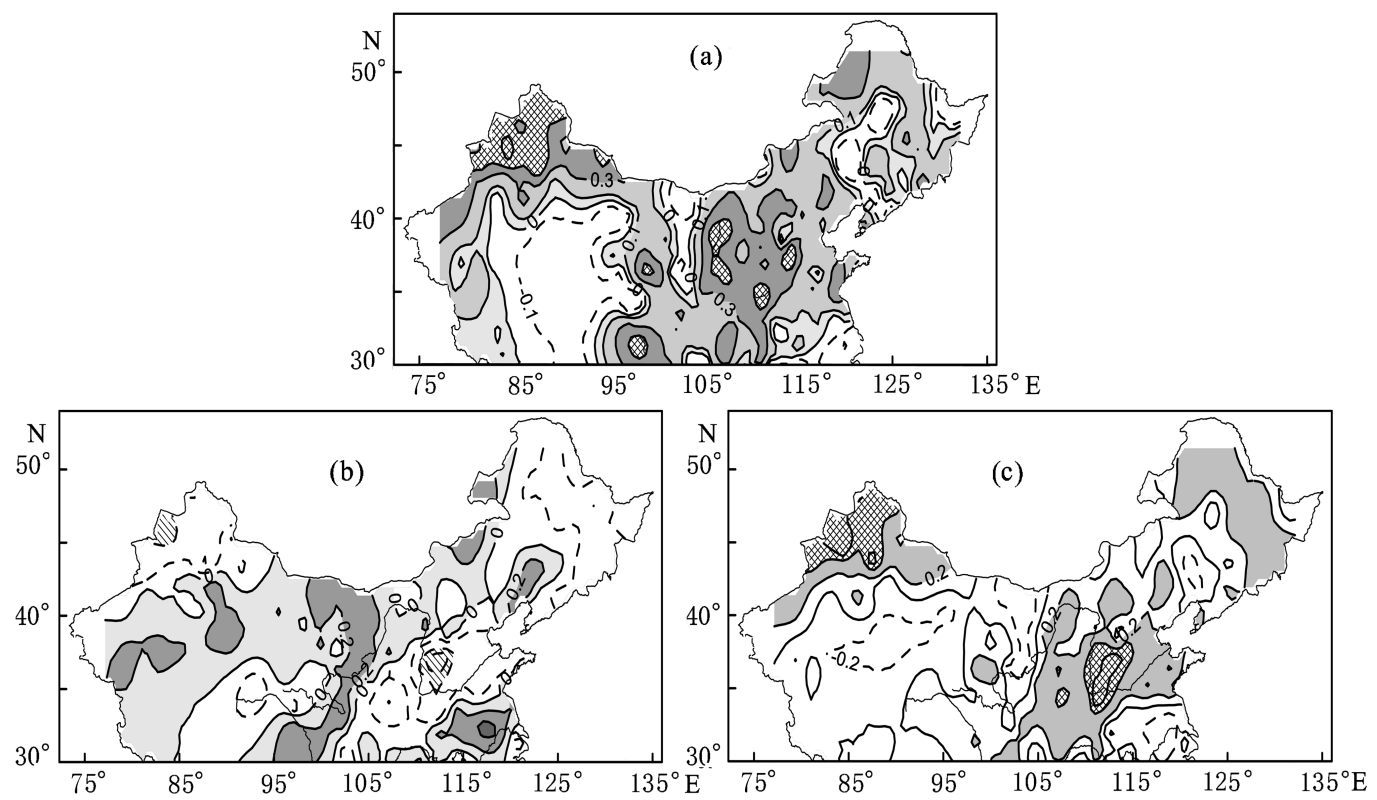

Fig. 7 Same as Fig. 5 but for (a) summer rainfall and summer NDVI, (b) summer AT and summer NDVI, (c) summer API and summer NDVI

The MIR is higher in MBZ, which indicates the increase of vegetation is higher in these areas in growing seasons. Spring and summer are the major seasons for the increase of water and AT, which indicates the vegetation increases significantly in MBZ in the major increasing seasons of water and AT. From this we can see that the reaction of vegetation to climate is sensitive in MBZ.

In summary, the influence of climate on vegetation varies with different areas for different climate backgrounds. The influence of climate on vegetation is more significant in MBZ with respect to monsoon and non-monsoon regions. The sensitive reaction of vegetation to climate in MBZ indicates the special character of MBZ. And it is also the meaning of this study. Water and heat vary significantly in MBZ, which is the sensitive area for the response of vegetation to climate change, and also the area where annual change of duststorms is significant ${ }^{[22]}$. 
Ou T H et al.: Vegetation Variations along the Monsoon Boundary Zone in East Asia

\section{CONCLUSIONS}

By analyses of the NDVI and station climate data in 1982 1999, we have studied the location of MBZ of the East Asia monsoon and the influence of climate on vegetation in MBZ. We got the following conclusions:

(1) For the definition of MBZ of the East Asia Monsoon, we use the annual mean rainfall between 300mm and $500 \mathrm{~mm}$, considering the marching and retreating of rain belts during stronger and weaker monsoon years, and the relative variations of precipitation during stronger and weaker monsoon years. We define the location of $300 \mathrm{~mm}$ rainfall of stronger monsoon years is the northern margin of MBZ, and the southern margin of MBZ is defined by the location of $500 \mathrm{~mm}$ rainfall of weaker monsoon years. In this way the location of MBZ of East Asia Monsoon has been defined.

(2) The influence of climate on vegetation varies from place to place, from season to season. For northern China, the change of AT influences vegetation largely in spring and precipitation influences the vegetation largely in summer. Precipitation influences the vegetation largely in high-latitude areas and AT influences the vegetation largely in low-latitude areas. There is delayed influence of precipitation on vegetation.

(3) In MBZ, due to influence of the interannual variability of the monsoon and cold and dry west wind, the interannual variability of vegetation changes largely, and the influence of climate on vegetation is significant in this area.

\section{ACKNOWLEDGMENTS}

This work was supported by the National Natural Science Foundation of China (40475032) and the Major State Basic Research Development Program of China (2006CB400504).

\section{REFERENCES}

[1] Fu C. Transitional climate zone and biome boundaries. In: Hansen A J, Castri F eds. Landscape Boundaries, Ecological Studies 92. New York: Springer-Verlag, 1992. 394 402

[2] Shi P J, Ha S. Comparison between Holocene environmental changes in north China agro-pastoral zone and Africa Sahelian belt. Earth Science Frontiers, 2002, 9(1): 121 128

[3] Shi Z T, Zhang L Y, Su G W. Natural disasters and their formation causes on Chinese monsoon marginal belt. J. Catastrophology (in Chinese), 1994, 9(4): 59 64

[4] Xu X K, Lin Z H, Xue F, et al. Correlation analysis between meteorological factors and the ratio of vegetation cover. Acta Eclogica Sinica (in Chinese), 2003, 23(2): 221 230

[5] Piao S L, Fang J Y, Chen A P. Seasonal dynamics of terrestrial primary production in response to climate change in China. Acta Botanica Sinica, 2003, 45(3): 269 275

[6] Li X B, Shi P J. Sensitivity analysis of variation in NDVI, temperature and precipitation in typical vegetation types across China. Acta Phytoecologica Sincia (in Chinese), 2000, 24(3): 379 382

[7] Fang Jingyun, Piao Shilong, Tang Zhiyao, et al. Interannual variability in net primary production and precipitation. Science, 2001, 293: 1723 (in Technical Comments)

[8] Piao S L, Fang J Y, Zhou L M, et al. Interannual variations of monthly and seasonal Normalized Difference Vegetation Index (NDVI) in China from 1982 1999. J. Geophys. Res., 2003, 108(D14): 4401

[9] Zhang J H, Fu C B, Yan X D, et al. Global respondence analysis of lai versus surface air temperature and precipitation variations. Chinese J. Geophys. (in Chinese), 2002, 45(5): 631 637

[10] Justice C O, Townshend J R G, Holben B N, et al. Analysis of the phenology of global vegetation using meteorological satellite data. Int. J. Remote Sens., 1985, 6: 1271 1318

[11] Tucker C J, Sellers P J. Satellite remote sensing of primary production. Int. J. Remote Sens., 1986, 7: 1395 1416

[12] Elaine M. Global vegetation and land use: high-resolution data bases for climate studies. J. Climate Appl. Meteror., 1983, 22: $474 \sim 500$

[13] Moulin S, Kergoat L, Viovy N, et al. Global-scale assessment of vegetation phenology using NOAA/AVHRR satellite measurements. J. Climate, 1997, 10: 1154 1170 
[14] Braswell B H, Schimel D S, Linder E, et al. The response of global terrestrial ecosystems to interannual temperature variability. Science, 1997, 278: 870 873 (in Reports)

[15] Graham D, Farquhar. Climate change: carbon dioxide and vegetation. Science, 1997, 278: 1411 (in Perspectives)

[16] Josep Peñuelas, Iolanda Filella. Phenology: Responses to a warming world. Science, 2001, 294: $793 \sim 795$ (in Perspectives)

[17] Gong D Y, Ho C H. Detection of large-scale climate signals in spring vegetation index (normalized difference vegetation index) over the Northern Hemisphere. J. Geophys. Res-Atmos, 2003, 108(D16): Art. No. 4498 AUG 20

[18] Qian W, Deng Y, Zhu Y, et al. Demarcating the worldwide monsoon. Theor. Appl. Climatol., 2002, 71: 1 16

[19] Huang R H, Zhou L T, Chen W. The progresses of recent studies on the variabilities of the East Asian monsoon and their causes. Adv. in Atmospheric Sciences, 2003, 20(1): 55 69

[20] Tao S Y, Zhao P, Li W, et al. On the process of summer monsoon onset over East Asia. Climatic and Environmental Research (in Chinese), 2000, 5(4): 345 355

[21] Zhu C W, He J H, Wu G X. East Asian monsoon index and its interannual relationship with large scale thermal dynamic circulation. Acta Meteorologica Sinica (in Chinese), 2000, 58(4): 391 402

[22] Zou X K, Zhai P M. Relationship between vegetation coverage and spring duststorms over northern China. J. Geophys. Res., 2004, 109, D03104, doi: 10.1029/2003JD003913 